\title{
Intranasal insulin administration does not modulate incretin secretion, gastric emptying, and appetite in healthy young adults
}

Yoshikazu Hirasawa ${ }^{1}$, Hisayo Yokoyama ${ }^{1,2}$, Nooshin Naghavi $^{1}$, Yoshihiro Yamashina ${ }^{1}$, Ryosuke Takeda $^{1}$, Akemi Ota $^{1}$, Daiki Imai $^{1,2}$, Tomoaki Morioka $^{3}$, Masanori Emoto ${ }^{3}$ and Kazunobu Okazaki ${ }^{1,2}$

${ }^{1}$ Environmental Physiology for Exercise, Osaka City University Graduate School of Medicine, Osaka, Japan

${ }^{2}$ Research Center for Urban Health and Sports, Osaka City University, Osaka, Japan

${ }^{3}$ Metabolism, Endocrinology and Molecular Medicine, Osaka City University Graduate School of Medicine, Osaka, Japan

\begin{abstract}
Intranasal insulin (INS) administration reduces food intake and body weight in humans. It remains unclear whether the intranasal delivery of INS to the brain affects incretin secretion via the brain-gut axis. In the present study, we examined the effect of intranasal INS administration on glucagon-like peptide-1 (GLP-1) secretion, gastric emptying, and appetite. Thirteen normal-weight, healthy, young volunteers (age $21.2 \pm 2.9$ (SD) years) participated in a randomized single-blind, crossover study. Sixteen puffs of regular INS (10 IU; total dose, $160 \mathrm{IU})$ or normal saline as a placebo $(0.1 \mathrm{~mL}$, with a total dose of $1.6 \mathrm{~mL})$ were intranasally administered in a random order after an overnight fast. Afterward, a fixed meal test, including $1,500 \mathrm{mg}$ paracetamol to measure gastric emptying, was performed in each participant. Blood glucose, INS, the active form of GLP-1, paracetamol, and postprandial satiety (measured using the visual analog scale) levels were evaluated during the 180-min meal test. Meal intake similarly induced the elevation of blood glucose, INS, and GLP-1 levels in both trials. The total increases in blood glucose, INS, and GLP-1 levels during the meal test evaluated by the area under the curve were not different between the trials. Gastric emptying velocity and postprandial satiety were not significantly different either. In conclusion, we could find no significant effect of intranasal delivery of INS to the brain on postprandial GLP-1 secretion, gastric emptying, or postprandial satiety in the present study with healthy young adults.
\end{abstract}

\section{Introduction}

The role of insulin (INS) in the central nervous system (CNS) has attracted attention in the regulation of feeding behavior and energy homeostasis. Peripheral INS secreted by pancreatic $\beta$-cells according to food intake not only acts on the receptors distributed throughout skeletal muscles, liver, and adipose tissue but also reaches the CNS across the blood-brain barrier by receptor-mediated saturable transport in a blood INS level-dependent manner [1]. The detection of widespread INS receptors in murine CNS was first reported in the 1970s. Not long after, it was demonstrated that INS receptors were also expressed in human CNS [2,3], and that those are primarily located in the cerebral cortex, olfactory bulb, hippocampus, cerebellum, and hypothalamus [4]. Studies with rodents have shown that the administration of INS to the CNS acutely reduces the blood glucose level and food intake [5-8].

Intranasal administration of neuropeptidergic messengers enables direct delivery to the CNS along the olfactory nerves, without substantial absorption into the blood stream [9]. In fact, intranasal INS administration also increases INS level in the cerebrospinal fluid (CSF) without any relevant peripheral effects in human [10,11]. Intranasal INS administration to the CNS has enabled investigators to examine the role of CNS-specific INS functions. Notably, intranasal INS administration acutely reduces food intake and appetite [12] and chronically reduces body fat in healthy subjects [13]. These results suggest that increased INS levels in the CNS contribute to regulating glucose and energy metabolism, and feeding behavior in humans.

Glucagon-like peptide-1 (GLP-1), an incretin secreted from L-cells of the distal small intestine to the portal circulation, not only stimulates pancreatic $\beta$-cells to secrete INS but also suppresses appetite [14] and delays gastric emptying [15] via a central mechanism. The secretion of GLP-1 is biphasic: the rapid increase in blood GLP-1 level up to $30 \mathrm{~min}$ after oral ingestion is attributed to vagal nerve stimulation. Furthermore, INS also stimulates L-cells to secrete GLP-1 [16], and it has been reported that the GLP-1 responses to test meal were impaired in nondiabetic subjects with INS resistance [17]. Therefore, it is possible that high INS levels in the CNS induce GLP-1 secretion by central mechanism especially via vagal nerves. However, there is no animal or human report regarding the influences of elevated insulin levels in the CNS on gastrointestinal tract function including the secretion of GLP-1.

The aim of the present study is to investigate the impact of intranasal INS administration on GLP-1 secretion, gastric emptying, and appetite during meal test in healthy young subjects in a single blinded, crossover design, in order to clarify the role of elevated insulin levels in the CNS in incretin system in humans.

Correspondence to: Hisayo Yokoyama, MD, Ph.D, Environmental Physiology for Exercise, Osaka City University Graduate School of Medicine, 3-3-138, Sugimoto, Sumiyoshi-ku, Osaka, Osaka, 558-8585, Japan, Tel: +81-6-6605-2947; Fax: +81-6-6605-2947; E-mail: yokoyama@sports.osaka-cu.ac.jp

Key words: intranasal insulin administration, central nervous system, GLP-1, gastric emptying, appetite

Received: May 31, 2016; Accepted: June 14, 2016; Published: June 17, 2016 


\section{Materials and methods}

\section{Subjects}

Thirteen healthy young adults were recruited from the students and the staffs aged 18-40 years in Osaka City University. We excluded subjects who had a history of ischemic heart disease, chronic heart failure, hypertension [resting systolic blood pressure (BP) $>140 \mathrm{mmHg}$ and/or diastolic $\mathrm{BP}>90 \mathrm{mmHg}$ ), diabetes, obesity [body mass index (BMI) over $30 \mathrm{~kg} / \mathrm{m}^{2}$ ], or nasal disorder. Written informed consent was obtained from all participants. The study protocol was approved by the Institutional Review Board of Osaka City University Graduate School of Medicine (approval No. 2826) and registered at the University Hospital Medical Information Network-Clinical Trial Registry (study ID: UMIN 000014153). This study also conformed to the standard set by the Declaration of Helsinki.

\section{Study design}

Our study is a randomized, single-blind, crossover study. All subjects visited our laboratory at Osaka City University on two separate days at least 1 week apart for two trials, the INS and the placebo (PL) trials, in random order.

The study protocol is shown in Fig. 1. In each trial, the experimental session was started at $0900 \mathrm{~h}$ after a 12-h fast. Throughout the experiment, subjects rested in Fowler's position on a bed in a quiet room at a constant temperature $\left(\sim 22^{\circ} \mathrm{C}\right)$. They were allowed to read and write quietly. An intravenous cannula was placed in the cubital vein and blood samples were collected for baseline measurements of glucose, INS, and GLP-1 levels. Then INS or PL was intranasally administered, followed by the ingestion of a fixed test meal. Blood samplings were repeated immediately after intranasal dosing and every 15-30 min after the test meal for $180 \mathrm{~min}$. The assessments of appetite were also performed over the same period before and after the meal.

\section{Intranasal administration}

After the baseline blood sampling and appetite assessment, 16 10IU puffs (eight per naris, alternating; total dose, 160 IU INS) of regular INS (Novolin ${ }^{\circledR}$ R, Novo Nordisk Pharma, Bagsvaerd, Denmark) or, for the PL trials, normal saline as PL $0.1 \mathrm{~mL}$, were intranasally administered in 1-min intervals, amounting to a total dose of $1.6 \mathrm{~mL}$. INS and PL were administered using a plastic nasal pump spray bottle (AS ONE Co., Osaka, Japan) that fills the nasal cavity with aerosol, enabling the solution to effectively target the olfactory epithelium. The dose of intranasal INS administration used here has been shown effective in stimulating INS receptors in the CNS without affecting peripheral blood INS levels in healthy humans [12,18-20].

\section{Test meal and estimation of gastric emptying velocity}

Immediately after the intranasal dosing, the subjects consumed a fixed test meal with $100 \mathrm{~mL}$ of water within $15 \mathrm{~min}$. The test meal consisted of chicken cream (Kewpie Co., Tokyo, Japan) and $200 \mathrm{~mL}$ of liquid-type nutritional food (Calorie Mate ${ }^{\circledR}$, Otsuka Pharmaceutical Co., Tokyo, Japan). Subjects were instructed to take them in this order. The test meal totaled $481 \mathrm{kcal}$ with $20.2 \mathrm{~g}$ of protein, $18.7 \mathrm{~g}$ of fat, and $56.5 \mathrm{~g}$ of carbohydrate. For the estimation of gastric emptying velocity, $1,500 \mathrm{mg}$ of ground paracetamol tablets (Calonal ${ }^{\circledR}$, Showa Yakuhin Kako Co., Ltd., Tokyo, Japan) was dissolved in the liquid-type nutritional food. Since ingested paracetamol is absorbed from the small intestine, serum paracetamol levels correlate with the rate of gastric emptying [21]. The areas under the curve (AUCs) for paracetamol were calculated from serum paracetamol levels during the postprandial period and used as the cumulative gastric emptying for $180 \mathrm{~min}$. Time until $50 \%$ of the test meal was emptied $\left(\mathrm{T}_{50 \%}\right)$, and the amount of the test meal remaining in the stomach at $60 \mathrm{~min}$ (\% remaining at $60 \mathrm{~min}$, $\left.\mathrm{AUC}_{60-180 \mathrm{~min}} / \mathrm{AUC}_{0-180 \mathrm{~min}}{ }^{*} 100\right)$ and $120 \mathrm{~min}$ (\% remaining at $120 \mathrm{~min}$, $\mathrm{AUC}_{120-180 \mathrm{~min}}^{60-180 \mathrm{~min}} / \mathrm{AUC}_{0-180 \text { min }}{ }^{0-180 \min }{ }^{*} 100$ ) was also calculated from the AUC for paracetamol [22].

\section{Assessment of appetite}

Appetite was evaluated by visual analogue scale (VAS) at baseline, before food intake and every $30 \mathrm{~min}$ during the postprandial period for $180 \mathrm{~min}$ as follows [23]. Subjects marked their satiety level between 0 and 100. "0" indicated "As hungry as I have ever felt" and "100" indicated "As full as I have ever felt," respectively. The length in $\mathrm{mm}$ from " 0 " to each mark on the $100 \mathrm{~mm}$ line was measured and used as an index of satiety.

\section{Anthropometrical measurements}

Percentage of body fat was estimated by bioelectrical impedance analysis using the body composition analyzer (Body Fat Analyzer TBF102, TANITA, Tokyo, Japan) before the first experimental session. BMI (in $\mathrm{kg} / \mathrm{m}^{2}$ ) was calculated as body weight $(\mathrm{kg})$ divided by height (m) squared.

\section{Laboratory measurements}

The collected blood samples were centrifuged for $15 \mathrm{~min}$ at 3,000 $\mathrm{rpm}$, and then serum and plasma were stored at $-80^{\circ} \mathrm{C}$ until assay. Plasma glucose level was measured by hexokinase UV methods. Serum INS and paracetamol levels were measured by chemiluminescent enzyme immunoassay and the enzymatic (aryl-acylamidase) method, respectively. To measure the level of the active forms of GLP-1 (GLP1 (7-36) amide and GLP-1 (7-37)), blood samples were immediately collected into the EDTA tubes containing aprotinin and $10 \mu \mathrm{L}$ of dipeptidyl peptidase IV inhibitor (Merck Millipore, Darmstadt, Germany) per $1.0 \mathrm{~mL}$ of blood, and the measurement was performed using a commercially available enzyme-linked immunosorbent assay (ELISA) kit (GLP-1, active form assay kit, Immuno-Biological Laboratories, Gunma, Japan) according to standard protocol. Regarding the performance of the kit, the intra-assay coefficient of variation was less than $6 \%$. The inter-assay coefficient was less than $11 \%$. The AUCs for glucose, INS, and GLP-1 were also calculated from their blood levels during the postprandial period for $180 \mathrm{~min}$ according to the trapezoidal rule.

\section{Statistical analysis}

Data are presented as mean \pm standard deviation (SD). The effects of intranasal INS administration and diet intake on appetite as well as postprandial glucose, INS, paracetamol, and GLP-1 levels were examined by two-way analysis of variance (ANOVA) with repeated measurements; this procedure was repeated for both successive intervals within trials and between the PL and the INS trials. Multiple post-hoc pairwise comparisons (Bonferroni method) were performed in the case of a significant time effect. In the case of significant trial effects, subsequent comparisons were performed by paired $t$-test. The test was also used for comparisons of the AUCs for postprandial glucose, INS, paracetamol, and GLP-1 levels, and for the comparisons of $\mathrm{T}_{50 \%}, \%$ remaining at 60 and 120 min between the trials. All statistical procedures were performed using SPSS statistical software package (version 21.0, IBM, NY, USA) for Windows (Microsoft Inc., WA, USA). $P$ values less than 0.05 were considered statistically significant. 


\section{Results}

Thirteen applicants who met the inclusion criteria were enrolled in the present study. The clinical characteristics of the subjects are summarized in Table 1.

As shown in Figure 2a and 2b, intranasal INS administration alone did not affect blood glucose or INS levels. While blood glucose and INS both rose as expected throughout each trial, neither blood glucose nor INS levels significantly differed between the trials throughout the 180-min observation (for glucose, main effect of time: $p<0.01$, main effect of trial: $p=0.829$, interaction effect of time $\times$ trial: $p=0.924$, Figure 2a; for INS, main effect of time: $p<0.01$, main effect of trial: $p=0.135$, interaction effect of time $\times$ trial: $p=0.380$, Figure $2 b$ ). Plasma GLP- 1 levels also increased after dietary intake without any difference between the trials (main effect of time: $p<0.01$, main effect of trial: $p=0.801$, interaction effect of time $\times$ trial: $p=0.800$, Figure $2 c$ ). In regard to gastric emptying, as shown in Figure $2 \mathrm{~d}$, there was no difference between trials in postprandial serum paracetamol levels (main effect of time: $p<0.01$, main effect of trial: $p=0.298$, interaction effect of time $\times$ trial: $p=0.291$ ) or in the AUCs for paracetamol. No difference was found in $\mathrm{T}_{50 \%} \%$ remaining at $60 \mathrm{~min}$, or \% remaining at $120 \mathrm{~min}$ (Figure $3 \mathrm{a}-\mathrm{c}$ ). Postprandial satiety was also similar between the trials (main effect of time: $p<0.01$, main effect of trial: $p=0.738$, interaction effect of time $\times$ trial: $p=0.454$, Figure $2 \mathrm{e}$ ).

\section{Discussion}

The aim of the present study was to examine the effect of high INS state in the CNS on postprandial secretion of GLP-1 using the method of intranasal administration of INS which enables to assess CNS-specific INS functions. A major finding was that any change in the secretion of GLP-1, kinetics of gastric emptying, or satiety after meal intake was not detected by intranasal administration of INS in our healthy, young subjects.

To the best of our knowledge, this is the first report to examine the effect of nasal INS administration on postprandial GLP-1 secretion. Nutrient ingestion is the primary stimulus for L-cells to secrete GLP-

Table 1. Clinical characteristics of subjects.

\begin{tabular}{|l|c|}
\hline Sex, male/female & $10 / 3$ \\
\hline Age, years & $21.2 \pm 2.9$ \\
\hline BMI, $\mathrm{kg} / \mathrm{m}^{2}$ & $20.0 \pm 1.4$ \\
\hline Body fat, $\mathrm{kg}$ & $9.0 \pm 3.3$ \\
\hline Body fat percentage, $\%$ & $15.9 \pm 5.7$ \\
\hline Systolic blood pressure, $\mathrm{mmHg}$ & $118 \pm 10$ \\
\hline Diastolic blood pressure, $\mathrm{mmHg}$ & $74 \pm 8$ \\
\hline Fasting plasma glucose, $\mathrm{mmol} / \mathrm{L}$ & $4.9 \pm 0.5$ \\
\hline Fasting serum insulin, $\mathrm{pmol} / \mathrm{L}$ & $24.7 \pm 19.5$ \\
\hline
\end{tabular}

Data are presented as mean $\pm \mathrm{SD}$.

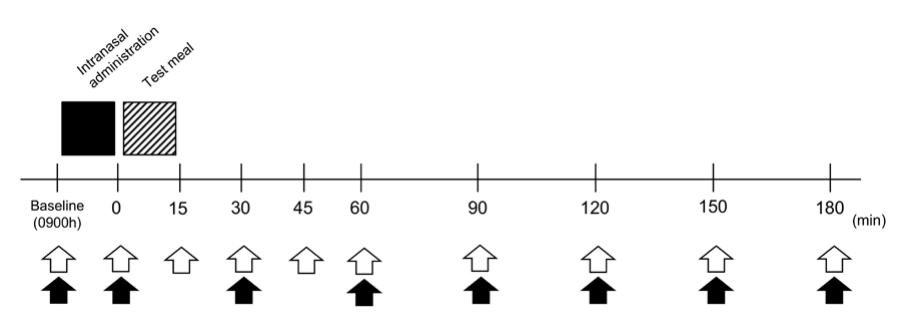

Figure 1. Experimental protocol. Black square indicates intranasal administration, and the hatched square indicates test meal intake. Blood samplings are indicated by white arrows and assessments of appetite by black arrows.
1. However, although L-cells are located on the distal small intestine, postprandial GLP-1 secretion shows a biphasic pattern, with an initial rapid rise in circulating GLP-1 levels 15-30 min after a meal and a second peak at 90-120 min. Therefore, the first phase of GLP-1 secretion is thought to be mediated by a neuroendocrine loop; that is, the passage of glucose or fat through the duodenum signals L-cells via the vagal nerve $[17,24]$. A previous study has demonstrated that GLP1 secretion was completely inhibited by subdiaphragmatic vagotomy, and contrarily increased by activation of the efferent celiac branch of the vagal nerve [25]. In addition to luminal nutrients, some circulating hormones and neuropeptides may modulate GLP-1 secretion. Lim et al. have demonstrated that human L-cells express INS receptors and that circulating INS stimulates GLP-1 secretion [16]. Taking their findings into consideration, it is possible that postprandial INS elevation augments GLP-1 secretion by a positive feedback mechanism. Because the delivery of INS to the brain using intranasal administration mimics the increased INS level in the CNS caused by food intake and enables to assess CNS-specific INS functions, we expected that intranasal INS administration would increase postprandial GLP-1 secretion through vagal efferent pathway to L-cells. However, contrary to expectation, intranasal INS administration did not affect postprandial GLP-1 levels in the present study. The primary mechanism of GLP-1 secretion may be portal hyperinsulinemia or the peripheral vagal loop between the duodenum and distal small intestine, and INS in the CNS may not be involved in modulating postprandial GLP-1 secretion. This is the main reason why nasal administration of INS failed to affect GLP-1 secretion. In addition, because healthy subjects in the present study had intact GLP-1 secretion, intranasal INS administration may have not resulted in a further increase in postprandial GLP-1 levels. To address this issue, studies are needed to examine whether intranasal INS administration increases postprandial GLP-1 secretion in subjects with impaired GLP1 secretion due to INS resistance or type 2 diabetes $[17,26]$.

To date, it has been reported that delivery of INS to the brain by the infusion into the cerebral ventricle reduced food intake in animals $[5,6]$. Although the phenomenon was also demonstrated in human studies, there is some inconsistency among the results. Benedict et al. reported that intranasal administration of INS before a meal reduced food intake in men but not women [12]. However, a neuroimaging experiment demonstrated that intranasal administration of INS altered food-related brain activity in both men and women [27]. In contrast, Hallschmid et al. demonstrated that, while intranasal administration of INS selectively reduced the palatability of chocolate cookies, it failed to alter the palatability of other cookies or total calorie intake [20]. The authors have also shown that the alteration in palatability was induced only by postprandial administration of INS but not by administration in fasting state. Thus the anorexigenic response to INS in the CNS seems to vary by gender, food palatability, and timing of INS administration. These may be reasons why intranasal administration of INS before a meal did not affect appetite in the present study, in which the majority of the subjects were men and the test meal did not have high palatability.

Studies have also suggested that intranasal INS administration acutely improves INS sensitivity. Benedict et al. demonstrated that preprandial intranasal INS administration reduced postprandial serum INS and C-peptide levels [19]. In studies with rats, it has been reported that INS infusion into the cerebral ventricle directly inhibited hepatic gluconeogenesis via the brain-liver axis mediated by the vagal nerve $[7,8]$. The findings by Obici et al. also demonstrated that a selective destruction of hypothalamic INS receptors reduced 
a
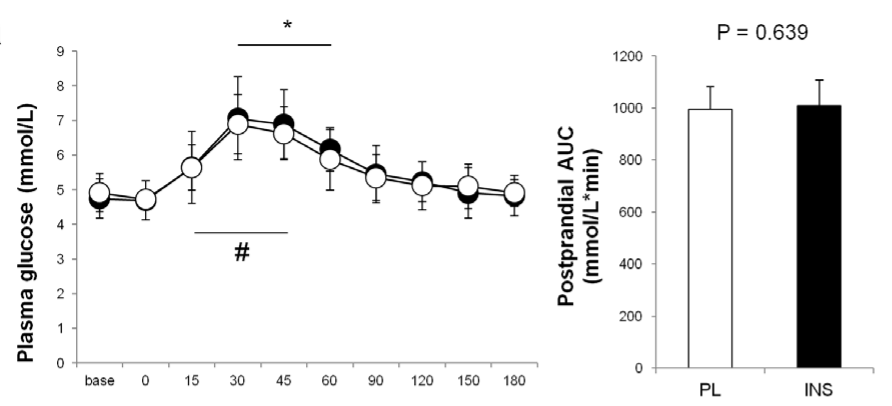

b
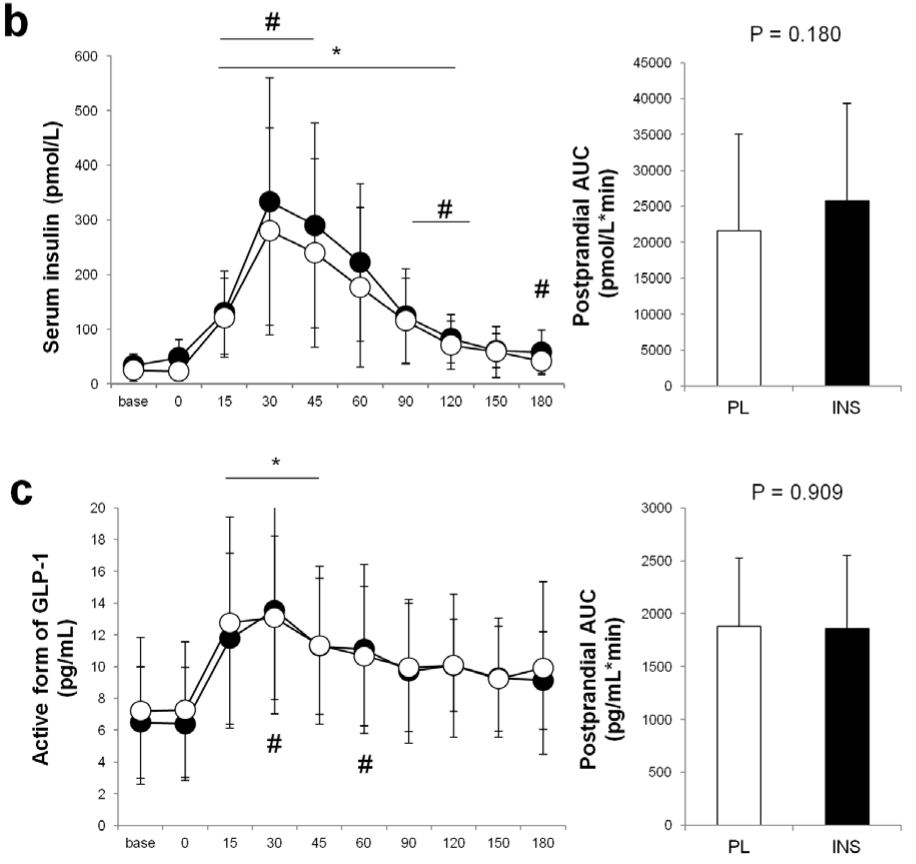
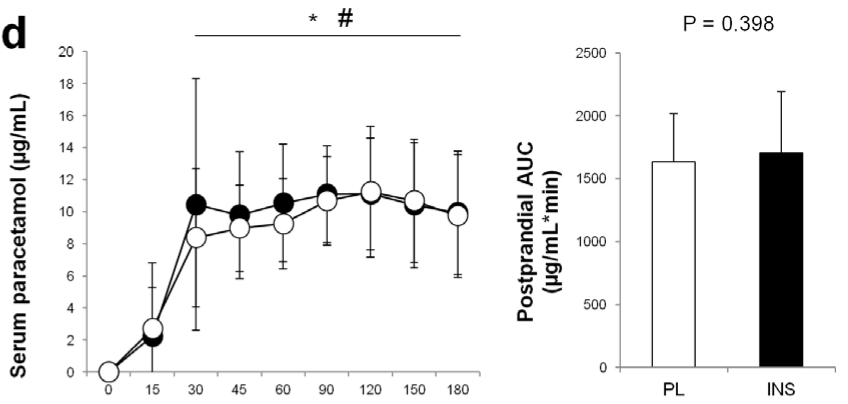

e

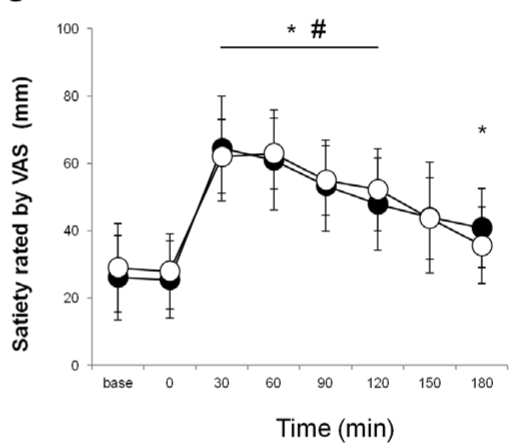

Time (min)

Figure 2. Comparisons of postprandial blood levels of parameters between the trials. Blood glucose (a), insulin (b), active form of glucagon-like peptide-1 (c), and paracetamol (d) levels, and satiety rated by visual analogue scale (VAS) (e) in the placebo (PL) and the insulin (INS) trials are indicated by white and black circles, respectively. The white and black bars in each right panel indicate the areas under the curve (AUCs) for the PL and the INS trials, respectively. All values are presented as means \pm SD. $*: p<0.05$ vs. baseline in the PL trial. *: $p<0.05$ $v s$. baseline in the INS trial.

hepatic INS sensitivity and resulted in marked increases in hepatic glucose production compared with control animals, although they had similar blood INS levels [28]. Thus INS in the CNS may be involved in peripheral glucose homeostasis by modulating hepatic INS action and may reduce postprandial INS demand.

In contrast, other human studies with postmenopausal women and obese subjects demonstrated that neither the serum INS nor the C-peptide level was affected by intranasal INS administration $[18,29]$. The results in the present study, in which postprandial serum INS levels were also unaffected by intranasal INS administration, are consistent with those by the authors. Although it was unclear whether endogenous INS secretion was reduced by intranasal INS administration in our subjects because we did not evaluate serum C-peptide levels, the controversy may be due to intact INS sensitivity of healthy, lean subjects in our study in addition to the difference in the timing of intranasal INS administration. In the future, human studies are needed to elucidate the effect of delivery of INS to the brain on hepatic glucose production.

A previous study reported that intranasal INS administration induced an immediate albeit slight increase in serum INS levels accompanied by a slight decrease in plasma glucose levels [19]. The author speculated that the elevation in serum INS levels may have been caused by a small portion of the administered INS that was absorbed systemically via nasal mucosa. Furthermore, as mentioned above, INS in the CNS seems to inhibit hepatic glucose production via vagal nerve, and this may be another reason why intranasal INS administration reduces plasma glucose level. However, blood INS and glucose levels were not affected by intranasal INS administration alone in the present study, and the result was similar to most other previous studies $[18,27,29]$. Nevertheless, blood glucose levels in our study remained within the euglycemic range. Therefore, intranasal INS administration does not seem to have relevant peripheral effects [11].

There are some limitations in the present study. First, GLP-1 and paracetamol levels at $180 \mathrm{~min}$ after meal intake remained higher than those at baseline. It may be possible that a longer observation could detect the differences in postprandial GLP-1 and paracetamol levels between the trials. Second, we could not directly measure the INS levels in the CNS. Therefore, it is possible that the $160 \mathrm{IU}$ of INS administration caused heterogeneous elevation of INS levels in 

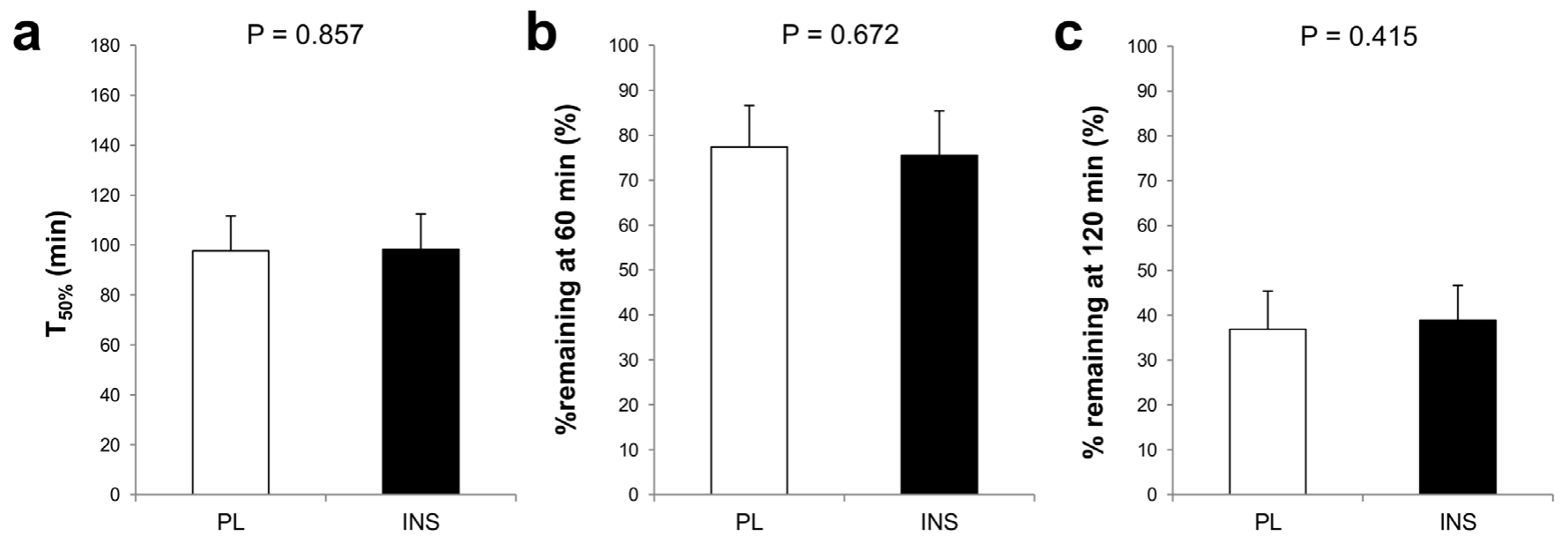

Figure 3. Comparisons of the indices of gastric emptying velocity between the placebo (PL) and the insulin (INS) trials. $\mathrm{T}_{50 \%}$ (a), $\%$ remaining at 60 min (b), and $\%$ remaining at 120 min (c) in the placebo (PL) and the INS trials are indicated by white and black bars. All values are presented as means \pm SD.

the CSF among the subjects, and the differences in INS levels in the CSF may have affected the results in the present study. However, we adopted the dose of INS according to those by previous reports [12,18$20,27,29]$, which verified high INS levels in the CSF by the same dose of administered INS as our studies [10].

\section{Conclusions}

Delivery of INS to the brain by intranasal administration before a meal does not influence postprandial GLP-1 secretion, gastric emptying, or postprandial satiety in healthy young adults. Further studies are needed to elucidate the role of INS in the CNS as a regulator of energy homeostasis including the secretion of incretins.

\section{Authors' contributions}

All authors contributed extensively to the work presented in this paper. Hisayo Yokoyama designed and supervised the experiments, data collection and interpretation, statistical analysis and drafting the manuscript. Yoshikazu Hirasawa performed experiments, acquisition of data, analysis and wrote the paper. Nooshin Naghavi, Yoshihiro Yamashina, Ryosuke Takeda, and Akemi Ota supported the acquisition and interpretation of the data. Tomoaki Morioka and Masanori Emoto discussed the results at all stage and commented on the manuscript. Daiki Imai, Tomoaki Morioka, Masanori Emoto, and Kazunobu Okazaki contributed to revising the manuscript critically for important intellectual content. All authors read and approved the final manuscript.

\section{Acknowledgments}

We would like to thank our volunteers for their time and participation in this investigation.

\section{Competing interest}

None of the authors have any potential conflicts of interest associated with this research.

\section{References}

1. Woods SC, Seeley RJ, Baskin DG, Schwartz MW (2003) Insulin and the blood-brain barrier. Curr Pharm Des 9: 795-800. [Crossref]

2. Havrankova J, Schmechel D, Roth J, Brownstein M (1978) Identification of insulin in rat brain. Proc Natl Acad Sci U S A 75: 5737-5741. [Crossref]
3. Schulingkamp RJ, Pagano TC, Hung D, Raffa RB (2000) Insulin receptors and insulin action in the brain: review and clinical implications. Neurosci Biobehav Rev 24: 855872. [Crossref]

4. Unger JW, Livingston JN, Moss AM (1991) Insulin receptors in the central nervous system: localization, signalling mechanisms and functional aspects. Prog Neurobiol 36: 343-362. [Crossref]

5. Woods SC, Lotter EC, McKay LD, Porte D Jr (1979) Chronic intracerebroventricular infusion of insulin reduces food intake and body weight of baboons. Nature 282: 503505. [Crossref]

6. Porte D Jr, Woods SC (1981) Regulation of food intake and body weight in insulin Diabetologia 20 Suppl: 274-280. [Crossref]

7. Obici S, Zhang BB, Karkanias G, Rossetti L (2002) Hypothalamic insulin signaling is required for inhibition of glucose production. Nat Med 8: 1376-1382. [Crossref]

8. Pocai A, Lam TK, Gutierrez-Juarez R, Obici S, Schwartz GJ, et al. (2005) Hypothalamic K(ATP) channels control hepatic glucose production. Nature 434: 10261031. [Crossref]

9. Thorne RG, Emory CR, Ala TA, Frey WH 2nd (1995) Quantitative analysis of the olfactory pathway for drug delivery to the brain. Brain Res 692: 278-282. [Crossref]

10. Born J, Lange T, Kern W, McGregor GP, Bickel U, et al. (2002) Sniffing neuropeptides: a transnasal approach to the human brain. Nat Neurosci 5: 514-516. [Crossref]

11. Hallschmid M, Schultes B, Marshall L, Mölle M, Kern W, et al. (2004) Transcortical direct current potential shift reflects immediate signaling of systemic insulin to the human brain. Diabetes 53: 2202-2208. [Crossref]

12. Benedict C, Kern W, Schultes B, Born J, Hallschmid M (2008) Differential sensitivity of men and women to anorexigenic and memory-improving effects of intranasal insulin. J Clin Endocrinol Metab 93: 1339-1344. [Crossref]

13. Hallschmid M, Benedict C, Schultes B, Fehm HL, Born J, et al. (2004) Intranasal insulin reduces body fat in men but not in women. Diabetes 53: 3024-3029. [Crossref]

14. Turton MD, O'Shea D, Gunn I, Beak SA, Edwards CM, et al. (1996) A role for glucagonlike peptide-1 in the central regulation of feeding. Nature 379: 69-72. [Crossref]

15. Nakade Y, Tsukamoto K, Pappas TN, Takahashi T, et al. (2006) Central glucagon like peptide-1 delays solid gastric emptying via central CRF and peripheral sympathetic pathway in rats. Brain Res 1111: 117-121. [Crossref]

16. Lim GE, Huang GJ, Flora N, LeRoith D, Rhodes CJ, et al. (2009) Insulin regulates glucagon-like peptide-1 secretion from the enteroendocrine L cell. Endocrinology 150: 580-591. [Crossref]

17. Rask E, Olsson T, Söderberg S, Johnson O, Seckl J, et al. (2001) Impaired incretin response after a mixed meal is associated with insulin resistance in nondiabetic men. Diabetes Care 24: 1640-1645. [Crossref]

18. Krug R, Benedict C, Born J, Hallschmid M (2010) Comparable sensitivity of postmenopausal and young women to the effects of intranasal insulin on food intake and working memory. J Clin Endocrinol Metab 95:468-472. [Crossref] 
Hirasawa Y (2016) Intranasal insulin administration does not modulate incretin secretion, gastric emptying, and appetite in healthy young adults

19. Benedict C, Brede S, Schiöth HB, Lehnert H, Schultes B, et al. (2011) Intranasal insulin enhances postprandial thermogenesis and lowers postprandial serum insulin levels in healthy men. Diabetes 60: 114-118. [Crossref]

20. Hallschmid M, Higgs S, Thienel M, Ott V, Lehnert H (2012) Postprandial administration of intranasal insulin intensifies satiety and reduces intake of palatable snacks in women. Diabetes 61: 782-789. [Crossref]

21. Maddern G, Miners J, Collins PJ, Jamieson GG (1985) Liquid gastric emptying assessed by direct and indirect techniques: radionuclide labelled liquid emptying compared with a simple paracetamol marker method. Aust N Z J Surg 55: 203-206. [Crossref]

22. Näslund E, Bogefors J, Grybäck P, Jacobsson H, Hellström PM (2000) Gastric emptying: comparison of scintigraphic, polyethylene glycol dilution, and paracetamol tracer assessment techniques. Scand J Gastroenterol 35: 375-379. [Crossref]

23. Flint A, Raben A, Blundell JE, Astrup A (2000) Reproducibility, power and validity of visual analogue scales in assessment of appetite sensations in single test meal studies. Int J Obes Relat Metab Disord 24: 38-48. [Crossref]

24. Roberge JN, Brubaker PL (1993) Regulation of intestinal proglucagon-derived peptide secretion by glucose-dependent insulinotropic peptide in a novel enteroendocrine loop. Endocrinology 133: 233-240. [Crossref]

25. Rocca AS, Brubaker PL (1999) Role of the vagus nerve in mediating proximal nutrientinduced glucagon-like peptide-1 secretion. Endocrinology 140: 1687-1694. [Crossref]

26. Toft-Nielsen MB, Damholt MB, Madsbad S, Hilsted LM, Hughes TE, et al. (2001) Determinants of the impaired secretion of glucagon-like peptide-1 in type 2 diabetic patients. J Clin Endocrinol Metab 86: 3717-3723. [Crossref]

27. Guthoff M, Grichisch Y, Canova C, Tschritter O, Veit R, et al. (2010) Insulin modulates food-related activity in the central nervous system. J Clin Endocrinol Metab 95: 748755. [Crossref]

28. Obici S, Feng Z, Karkanias G, Baskin DG, Rossetti L (2002) Decreasing hypothalamic insulin receptors causes hyperphagia and insulin resistance in rats. Nat Neurosci 5 566-572. [Crossref]

29. Guthoff M, Stingl KT, Tschritter O, Rogic M, Heni M, et al. (2011) The insulinmediated modulation of visually evoked magnetic fields is reduced in obese subjects. PLoS One 6: e19482. [Crossref]

Copyright: (2016 Hirasawa Y. This is an open-access article distributed under the terms of the Creative Commons Attribution License, which permits unrestricted use, distribution, and reproduction in any medium, provided the original author and source are credited. 